\title{
Performance Assessment of Green Filtration System with Evaporative Cooling to Improve Indoor Air Quality (IAQ)
}

\author{
Chang Choo Khean, Tan Yong Yih, and Zahurin Bin Othman
}

\begin{abstract}
This paper focuses on the performance assessment of the green filtration system that incorporated with evaporative cooling that used to enhance indoor air quality. This system was invented in an attempt to thrive in a clean environment that becomes a solution for certain places. Indoor air quality (IAQ) and public health risk related to each other, it is due to the percentage of the city population that stays indoors rather than go outdoors. Indoor air contamination is originated from mixed origins such as volatile organic compounds (VOCs) and indoor airborne particulate matter (PM). The results show that the green filtration system manages to filter PM and VOCs in the air but not as efficient as modern air filters in the market. Furthermore, the evaporative cooling system possesses a huge deal in energy-saving within hot and arid climatic regions.
\end{abstract}

Index Terms-Green filtration, evaporative cooling, indoor air quality.

\section{INTRODUCTION}

Indoor air quality (IAQ) and public health risk related to each other, it is due to the percentage of the city population that stays indoors rather than go for outdoors, which is around 85 - $90 \%$ [1]. The United States Environmental Protection Agency classifies indoor air quality as one of the five national health threat [2]. Indoor air contamination is originated from mixed origins such as volatile organic compounds (VOCs) and indoor airborne particulate matter (PM). It was found that the green filtration system grows progressively as a favored approach for indoor air contaminant reduction [3], additionally, impart an encouraging workplace decoration. A Passive green filtration system can treat indoor air pollutants, like volatile organic compounds (VOCs) that predominantly extracted by greenery rhizosphere bacterium colony [4], plus $\mathrm{CO}_{2}$ which discarded along photosynthesis process [5]. Inversely proportional, dynamic systems that employ force ventilation, drive air along with substrate and planting bed foundation system that elevates the filtration and air purification aptitude of system. It is recommended that using a dynamic green filtration system for indoor air contaminants domination is a more empirical replacement to conventional mechanical practice which inherently assists in diminish city greenhouse gas emission [6].

Evaporative cooling is an approach that can be utilized to cool either air or water and even both by implementing

Manuscript received June 12, 2021; revised August 20, 2021.

Chang Choo Khean and Zahurin B. Othman are with the HVAC\&R Section of Universiti Kuala Lumpur, Malaysia France Institute, Bangi, Selangor, Malaysia (e-mail: chang@unikl.edu.my, zahurin@unikl.edu.my).

Tan Yong Yih is with the Project Department of Bond M\&E Sdn. Bhd., Malaysia (e-mail: suffian@bmesbjb.com.my). immense enthalpy of water vaporization. The repressed concept is to converse the sensible heat to latent heat throughout the evaporation of water, generate a declination in temperature and a rise in the humidity of the surrounding air. In contrast to the typical air conditioning system practice, it is evaluated that evaporative cooling systems possibly demand only around one-fourth of the electric consumption that vapour compression system that uses for air conditioning [7]. Moreover, evaporative cooling can also propose different substantial benefits, inclusive coherent operation, economical in terms of set up and maintenance costs, superb indoor air quality as fully fresh air is used, little pollution and reasonable top-class essential energy [8], [9]. Regarding thermal comfort, stand-alone evaporative cooling structure can designate the occupant requirement in tropical and dry conditions as the endmost relative humidity maintain in the scale of $60-70 \%$. Nevertheless, it is unmanageable to achieve the correlative outcome for the humid region because near-saturated conditions are demanded temperature drop needed. In such situation, hybrid structure like desiccant in the form of evaporative cooling are desired.

This paper presents an experimental assessment on green filtration systems with evaporative cooling in terms of several affecting factors for air filtration such as temperature, humidity, air velocity, particulate matter (PM) removal, $\mathrm{CO}_{2}$ level, volatile organic compounds (VOCs) and feasibility analysis on evaporative cooling in Malaysia. The outcome of this study focusing on providing a better understanding of green filtration comes with a cooling system.

\section{EXPERIMENTAL INSTRUMENTS AND METHODOLOGY}

\section{A. Testing Room}

The study was conducted in Universiti Kuala Lumpur Malaysia France Institute (UniKL MFI), Section 14 Bandar Baru Bangi, Malaysia. The location experiencing hot and rainy weather within the humid tropical zone with nearly uniform temperature throughout the year, rainfall acceptance is high in total. Humidity in the area is within the range of $65 \%$ - $85 \%$ with average weather temperature range $26.5^{\circ} \mathrm{C}$ and $31^{\circ} \mathrm{C}[10]$.

As for the room specification, it is a room located at Level 2 with a $100 \%$ panel ceiling board, and the total floor area is approximately $512 \mathrm{ft}^{2}$. The ceiling height is $11 \mathrm{ft}$. There are three (3) windows but only two (2) which can be opened for ventilation purpose. There is only an access door to the room. The appliances in the room are lighting using six (6) fluorescent lamp 36 watt each of them, two (2) unit of ceiling fans with power input 75 watt, one (1) unit of ceiling exposed VRV air conditioner with the capacity of 2.0 HP and two (2) sets of ducting come with fan for educational purpose. 


\section{B. Test Kit Specifications}

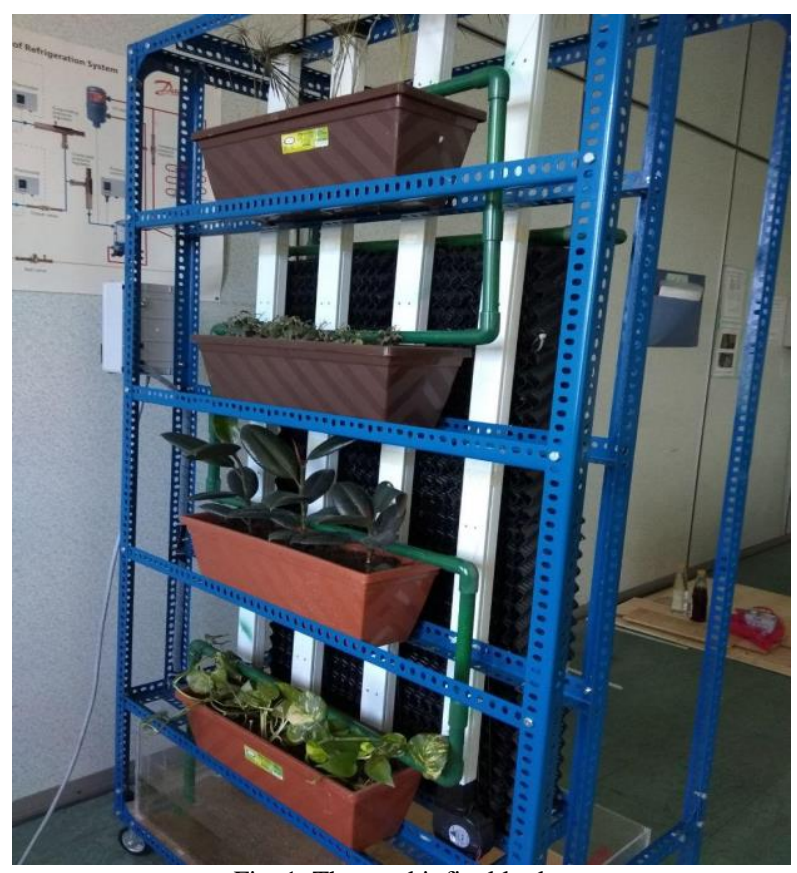

Fig. 1. The test kit final looks.

The test kit consists of several electric powered components such as a 55W AC aquarium pump, four (4) units of $12 \mathrm{~V} 2.94 \mathrm{~A}$ DC blower fan and inverter. Installed on the test kit is cooling tower PVC infill, electrical PVC trunking which acted as air carrier, PVC pipe and plastic acrylic aquarium at bottom of the unit with the capacity of 70 litres. The plants used in the test kit are Bamboo Palm, Chrysanthemum, Ficcus Plant, and Money Plant as shown in Fig. 1.

\section{Data Collection}

Data collection was done for the test room and test kit to measure the effectiveness of the green filtration system and the evaporative cooling effect. The data gathering for ambient and room temperature and relative humidity using Kima KH50 Data Logger were done for 28 days from 28 March to 24 April 2019, which is considered to be the best in determining the fluctuation of data because of weather change. While the Thermal Comfort instrument was used to measure the $\mathrm{CO}_{2}$ level, room pressure, relative humidity and temperature of the room from 11 April to 24 April 2019. For the test kit performance, the data collection was focused on the temperature, relative humidity, air velocity, particle measurement and TVOC measurement in front and rear of the test kit. The instrument used for measurement at the test kit are shown in Table I.

The data taken for the test kit was done for 2 days, that was from 22 - 23 April 2019 from 10 am to 12 pm for four (4) different kinds of plants in a closed room without any ventilation, and the only air conditioner was turned on. For the afternoon session where the temperature was at its peak, data was taken from $2 \mathrm{pm}$ to $4 \mathrm{pm}$. It was being done in an open room where the air conditioner was turned off and the ceiling fan was turned on. Air circulation was allowed to the test room via window and door in the open room condition. On the next day, VOC measurement was taken at 10 am where all VOCs gasses such as formaldehyde, benzene, xylene, toluene, and even carbon monoxide is released into closed room 5 minutes before taking the readings. The VOC measurements were taken in a certain distance, ranging from $0.25 \mathrm{~m}, 0.5 \mathrm{~m}$, and $1.0 \mathrm{~m}$ before it went through the test kit as illustrated in Fig. 2. All data taken after the test kit was carried out at a distance of $15 \mathrm{~cm}$ in front of the test kit. The effectiveness of evaporative cooling was determined. At first, the only blower fan was turned on instead of both blower fan and pump. The second measurement recorded when both the blower fan and pump were turned on at the same time. Every measuring point, there were three (3) to four (4) reading were taken to get an average reading which would show the best reading.

TABLE I: INSTRUMENT LIST

\begin{tabular}{|c|l|l|}
\hline No. & \multicolumn{1}{|c|}{ Instrument } & \multicolumn{1}{|c|}{ Measured parameter } \\
\hline 1. & $\begin{array}{l}\text { Amprobe RH \& Temperature } \\
\text { meter }\end{array}$ & $\begin{array}{l}\text { Relative humidity } \\
\text { temperature }\end{array}$ \\
\hline 2. & Kimo Vane Anemometer LV50 & Air velocity \\
\hline 3. & CEM Airborne Particle Counter & Particle count \\
\hline 4. & $\begin{array}{l}\text { Agnes Reese Professional } \\
\text { Formaldehyde TVOC meter }\end{array}$ & $\begin{array}{l}\text { Total Volatile Organic } \\
\text { Compound (TVOC) }\end{array}$ \\
\hline
\end{tabular}

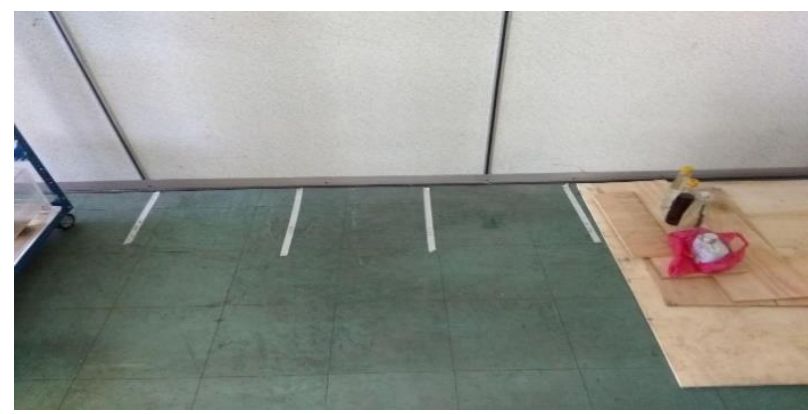

Fig. 2. The TVOC measurement points before the test kit.

\section{Effectiveness}

To measure the effectiveness of botanical components required different types of plants, as plant structure and arrangement are the main factors in filtering the air. For this purpose, two (2) types of structures were selected. The first type is the potted plant which are the Bamboo Palm, Chrysanthemum, and Ficcus Plant, and the second is a vining plant, Money Plants. The effectiveness of the green filtration system with evaporative cooling, data was collected and expressed in the form of a graph. Performance of the test kit can be calculated using the following formula:

$$
\eta=\left(1-\frac{\text { Temperature After Test kit }}{\text { Temperature Before Test kit }}\right) \times 100 \%
$$

Effectiveness of evaporative cooling in reducing the temperature of air passing through the test kit can be determined by using equation 1 . While equation 2 below was used to determine $\mathrm{RH}$ escalation in the air after passing through the test kit.

$$
\eta=\left(1-\frac{\text { Relative Humidity Before Test kit }}{\text { Relative Humidity After Test kit }}\right) \times 100 \%
$$

Equation 3 similar to the above but different in the variable as it was used in determining the filtration effectiveness of particulate matter (PM) according to each concentration. The $\mathrm{PM}$ fractions measured in this experiment started from 0.3 $\mu \mathrm{m}$ to $10 \mu \mathrm{m}$. 


$$
\eta=\left(1-\frac{\text { Particle Count After Test kit }}{\text { Particle Count Before Test kit }}\right) \times 100 \%
$$

Equation 4 was used to verify the percentage if there is some declination in VOCs after the test kit. It was divided into two gasses, which are formaldehyde and benzene.

$$
\eta=\left(1-\frac{\text { TVOCs After Test kit }}{\text { TVOCs Before Test kit }}\right) \times 100 \%
$$

\section{RESULT AND DISCUSSION}

\section{A. Ambient Temperature and Relative Humidity}

Both ambient temperature and relative humidity were collected using Kimo KH50 Data Logger. As illustrated in Fig. 3, KH50 recorded the maximum temperature, $34.4{ }^{\circ} \mathrm{C}$ at $2.30 \mathrm{pm}$ on the 14th April 2019, whilst the lowest was $22.8^{\circ} \mathrm{C}$ that happened on the 24 th of April. Relative humidity $82.9 \%$ was detected as the highest on the 23th April 2019 at $6.30 \mathrm{am}$, as it was raining in the morning, precipitation was $2 \mathrm{~mm}$ according to www.accuweather.com. The average temperature and relative humidity recorded by KH50 were $29.7^{\circ} \mathrm{C}$ and $70.36 \%$, respectively. Data measurement was 30 minutes interval between each reading.

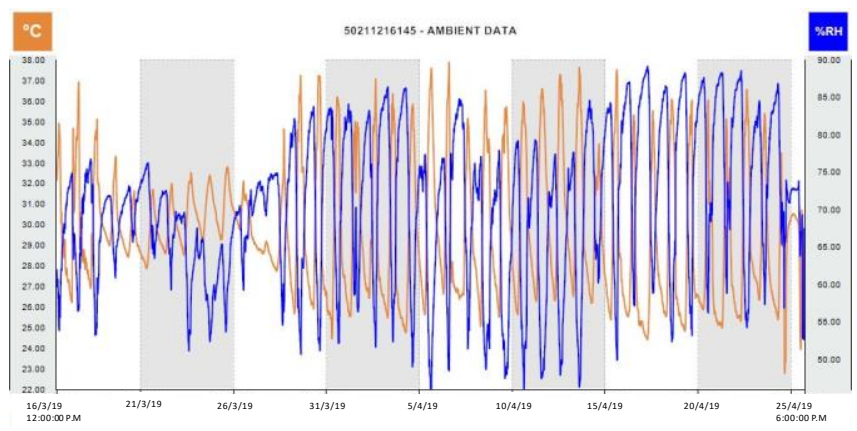

Fig. 3. Graph for ambient temperature and RH collected by Kimo KH50 from $16 / 3 / 19$ to $25 / 4 / 19$.

More than being said, consideration of test room conditions with the ambient condition also important. Starting from ambient temperature and RH evaluation, Data Logger KH50 shows a maximum point of the temperature reading $34.4{ }^{\circ} \mathrm{C}$ at $2.30 \mathrm{pm}$. According to the source of Wikipedia regarding Malaysia's temperature, the highest temperature was recorded at Chuping, Perlis on 9 April 1998 at $40.1{ }^{\circ} \mathrm{C}\left(104.2{ }^{\circ} \mathrm{F}\right)$. The lowest temperature (Official) was recorded at Cameron Highlands on 1 February 1978 at $7.8^{\circ} \mathrm{C}$ $\left(46.0^{\circ} \mathrm{F}\right)$. In terms of $\mathrm{RH}$, the minimum point $\mathrm{RH}$ should be considered. Based on KH50 data, the lowest RH recorded is $46.0 \%$. At this point, both temperature and $\mathrm{RH}$ data are reliable and accurate as compared to the Malaysian Standard (MS 1525) outdoor design parameter is $33.3{ }^{\circ} \mathrm{C}$ and $65 \%$ $\mathrm{RH}$.

\section{B. Test Room Temperature and Relative Humidity}

Fig. 4 shows the maximum temperature in the test room was $34.4{ }^{\circ} \mathrm{C}$ at $3.30 \mathrm{pm}$ on the 13th of April 2019. While the minimum was $22.8{ }^{\circ} \mathrm{C}$ on the 24th of April. Relative humidity $82.2 \%$ were recorded as the highest on the 22nd April 2019 at 8.30 am and the lowest was $47.5 \%$ at $1.30 \mathrm{pm}$ on the 23rd of March 2019. The average temperature and relative humidity recorded by $\mathrm{KH} 50$ were $29.82{ }^{\circ} \mathrm{C}$ and $69.73 \%$, respectively. The temperature and $\mathrm{RH}$ of the test room should not go higher than ambient readings. This is because the ambient is considered outside and surrounding while the test room is inside the building itself. For the test room result, both data acquired from different equipment are compared, the same method as the ambient. Equipment used were Data Logger KH50 too. The maximum temperature is $34.4{ }^{\circ} \mathrm{C}$ which is at $3.30 \mathrm{pm}$. While the minimum point of $\mathrm{RH}$ recorded is $47.5 \%$ at $1.30 \mathrm{pm}$.

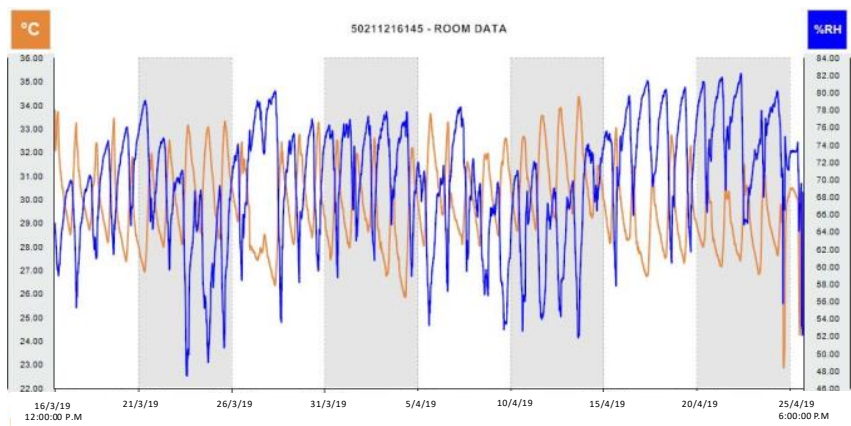

Fig. 4. Graph temperature and RH test room collected by Kimo KH50 from $16 / 3 / 19$ to $25 / 4 / 19$.

\section{C. $\mathrm{CO}_{2}$ Level in Test Room}

CO2 Level VS Number of Sample Per Minute in Test Room for 24 Days

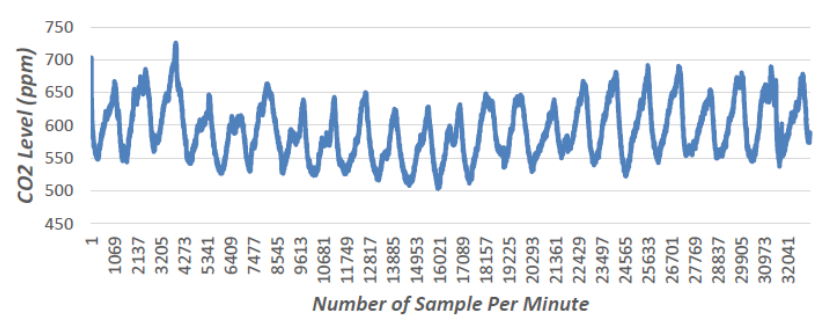

Fig. 5. CO2 level of test room data from thermal comfort instrument.

Fig. 5 above displays the $\mathrm{CO}_{2}$ level profile from the 1 st 23rd April 2019, which were taken at every minute interval. Total readings recorded were 32,263 points and it demonstrated a fluctuating trend, but it was still within the acceptable range from $500-700 \mathrm{ppm}$. But there was an incident that the $\mathrm{CO}_{2}$ level shot up above $700 \mathrm{ppm}$ which counted exactly $725.6 \mathrm{ppm}$ at 6.35 am on 4th April 2019. The average $\mathrm{CO}_{2}$ level in the test room was $592 \mathrm{ppm}$. During this period, the test room allowed ventilation from windows and ceiling fan was turned on. No occupant was allowed to enter the test room except during the irrigation of plants. To show a closer look at $\mathrm{CO}_{2}$ profile during the closed room where no ventilation was allowed, a data of 24 hours before the experiment was taken for monitoring purposes which were from 11.00 am of 22nd April 2019 to 11.00 am of 23rd April 2019 as illustrated in Fig. 6 below.

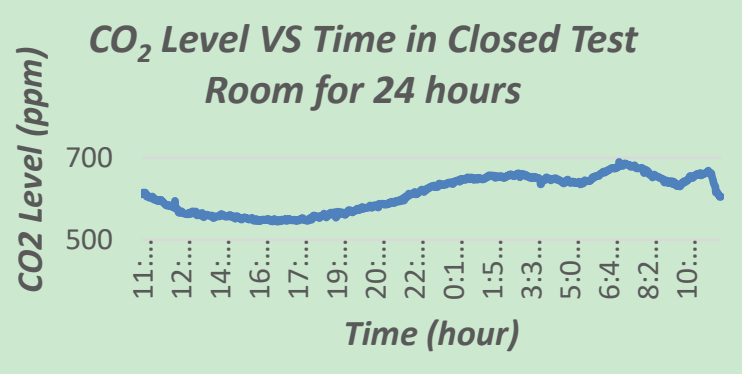

Fig. 6. $\mathrm{CO}_{2}$ level of closed test room from $11 \mathrm{am}, 22 / 4 / 19$ to $11 \mathrm{am}, 23 / 4 / 19$. 
Nevertheless, the $\mathrm{CO}_{2}$ profile was taken for graphing shows a piece of interesting information. It was mostly taken during open ventilation, almost the same as the variation of $\mathrm{CO}_{2}$ in a day which also called Seasonal and Diurnal $\mathrm{CO}_{2}$ pattern. To show it was not the same, a data of 24 hours in which there was no ventilation was allowed which was the closed room was taken and a graph was plotted, and its result was magnificent in which plant photosynthesis and breathing can be observed on a certain time.

\section{Reading Before and After Test Kit (Closed Room)}

\section{- Reading Before Test Kit - Morning}

Table II and Table III display the readings for temperature and relative humidity taken before and after/in front of the test kit, with the test condition as below. These readings were taken as the reference for the next experiments for comparison purposes.

Test condition:

1) Test kit's Fan ON/Pump OFF

2) Room Condition: A/C ON (Window \& Door Closed)

3) Ceiling Fan OFF

4) Time $=10.00 \mathrm{am}$

5) Measuring point location $=15 \mathrm{~cm}$ from the test kit

TABLE II: READINGS BEFORE THE TEST KIT

\begin{tabular}{|c|c|c|}
\hline \multirow{2}{*}{ Point } & \multicolumn{2}{|c|}{ Parameters } \\
\cline { 2 - 3 } & Room Temp, ${ }^{\circ} \mathrm{C}$ & Room RH, $\%$ \\
\hline 1 & 28.0 & 73.3 \\
\hline 2 & 27.9 & 73.0 \\
\hline 3 & 27.8 & 73.6 \\
\hline Average & 27.9 & 73.3 \\
\hline
\end{tabular}

TABLE III: READINGS AFTER/IN FRONT OF THE TEST KIT WITHOUT RUNNING THE PUMP IN A CLOSED ROOM

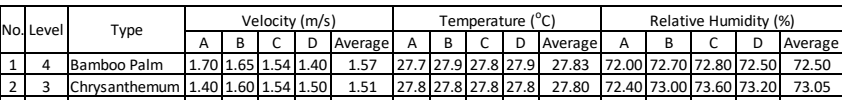
\begin{tabular}{|l|l|l|l|l|l|l|l|l|l|l|l|l|l|l|l|l|l|l|}
\hline 2 & 3 & Chrysanthemum & 1.40 & 1.60 & 1.54 & 1.50 & 1.51 & 27.8 & 27.8 & 27.8 & 27.8 & 27.80 & 72.40 & 73.00 & 73.60 & 73.20 & 73.05 \\
\hline 3 & 2 & Ficcus Plant & 1.40 & 0.90 & 1.60 & 1.40 & 1.33 & 27.8 & 27.8 & 27.8 & 27.8 & 27.80 & 73.00 & 73.00 & 73.60 & 73.20 & 73.20 \\
\hline
\end{tabular}

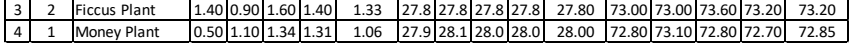

Test conditions:

1) Test Kit's Fan ON/Pump ON

2) Room Condition: A/C ON (Window \& Door Close)

3) Ceiling Fan OFF

4) Time $=10.00 \mathrm{am}$

5) Measuring points location $=15 \mathrm{~cm}$ from the test kit

Both dry bulb temperature and relative humidity decreased slightly after the test kit, where the air was blowing through the test kit with plant growth. The air was cooled after the plants. The effect will be more significant if more quantities and thicker of the plants are grown. Table IV shows the readings when the test kit's water pump was turned on. This provided an evaporative cooling effect while the water from the aquarium underneath the planter boxes was circulating from the pipes above the planter boxes to the aquarium through the cooling tower infill, which acts as a cooling pad. The air dry bulb temperature was further reduced when the water pump was $\mathrm{ON}$.

As shown in Fig. 7 above, the highest air velocity was through the Chrysanthemum plant which was $1.55 \mathrm{~m} / \mathrm{s}$ and the lowest air velocity experienced from a Money Plant that was $1.14 \mathrm{~m} / \mathrm{s}$. Fig. 8 shows the data on the dry bulb temperature after the pump is turned on. It can be due to the blockage of the leaves for a different type of plants. The temperature decreased for all plants, the highest temperature is Bamboo Palm which is $27.68^{\circ} \mathrm{C}$ and the lowest is $26.58^{\circ} \mathrm{C}$ by Ficcus Plant.

TABLE IV: READINGS AFTER TEST KIT WITH THE PUMP RUNNING IN A Closed RoOM

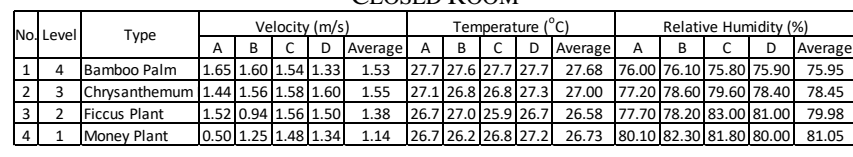

\section{TEST KIT VELOCITY VS PLANT TYPE IN CLOSED ROOM}

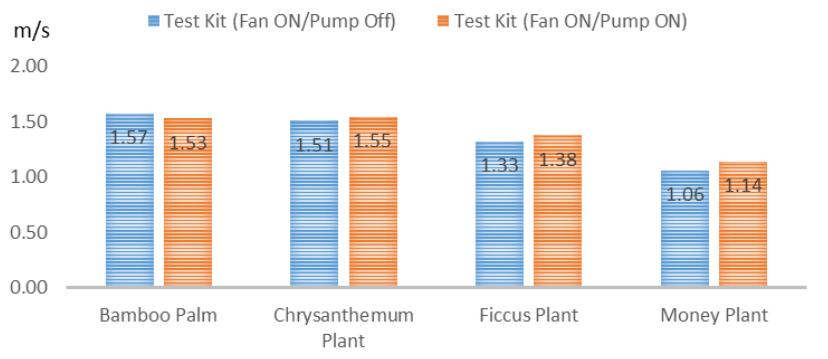

Fig. 7. Test kit velocity measurement in a closed room.

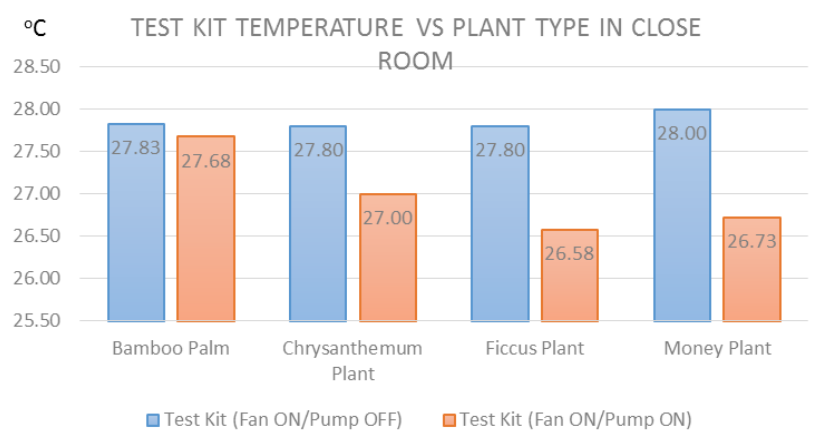

Fig. 8. Test kit temperature measurement in a closed room.

Based on Fig. 9 below, it shows the increased value of RH for all points taken. The maximum point acquired is $81.05 \%$ on the Money Plant and the minimum point is $75.95 \%$ on the Bamboo Palm. The value of RH gradually increasing from Bamboo Palm, Chrysanthemum, Ficcus Plant, and Money Plant. The RH percentage points increased due to the evaporative cooling effect from the water stream flowing down through the cooling tower infill. This directly will bring down the air temperature as shown in Fig. 9 below.

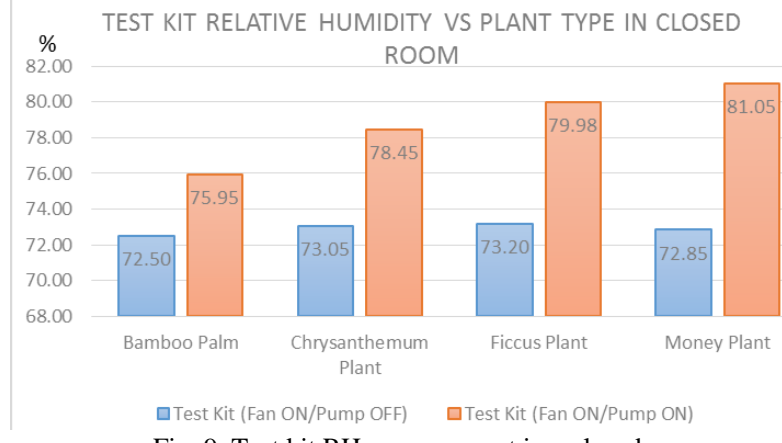

Fig. 9. Test kit RH measurement in a closed room.

Airborne particle count was taken using CEM Particle Counter Meter, and it was done in a closed room rather than an open room because closed room readings almost the same as environmental reading. There are three (3) states of data have been taken. The first set of reading was taken before the test kit, the second set was at the condition where only blower 
fan was turned on and the readings were taken after the test kit. Lastly, the reading taken after the test kit with both the blower fan and pump were turned on. The concentration of particles measured from the range of $0.3 \mu \mathrm{m}$ to $10 \mu \mathrm{m}$ as shown in Table $\mathrm{V}$.

TABLE V: PARTicle Count REAdings BEFore AND AFTER Test Kit
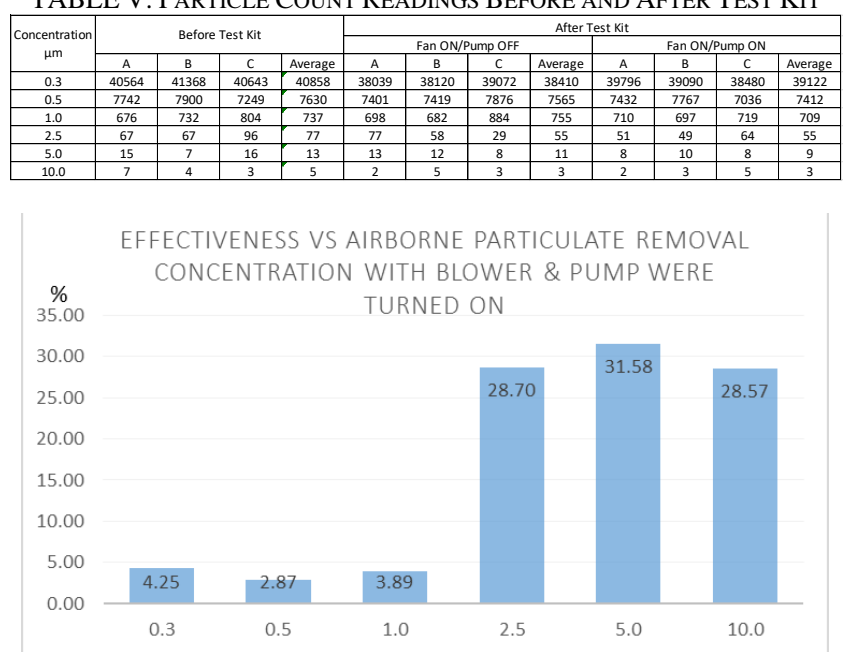

Fig. 10. Particle removal efficiencies for all concentration.

Fig. 10 displays the airborne particulate removal efficiency for different particulate sizes when both the blower and pump were turned on. The highest efficiency was shown by $31.58 \%$ at concentration PM5.0 and the lowest was $2.87 \%$ at concentration PM0.5. This is most likely due to the bigger particulate was easier to be washed away by the vertical water flow.

\section{E. Before and After Test Kit Reading (Open Room)}

- Reading Before Test Kit - Afternoon

\section{A $66.6 \% \mathrm{RH} / 31.6^{\circ} \mathrm{C}$ \\ B $\left.66.7 \% \mathrm{RH} / 31.4{ }^{\circ} \mathrm{C}\right\} \operatorname{Avg} 66.6 \% \mathrm{RH} / 31.5{ }^{\circ} \mathrm{C}$ \\ C $66.4 \% \mathrm{RH} / 31.4{ }^{\circ} \mathrm{C}$}

Test condition:

1) Test Kit $=($ Fan ON/Pump ON $)$

2) Room Condition $=\mathrm{A} / \mathrm{C}$ OFF (Window \& Door Open)

3) Appliance $=$ Ceiling Fan ON

4) Time $=2.00 \mathrm{pm}$

5) Length of Measurement Taken $=15 \mathrm{~cm}$ from test kit

TABLE VI: READINGS AFTER TEST KIT WITH THE PUMP RUNNING IN AN OPEN ROOM

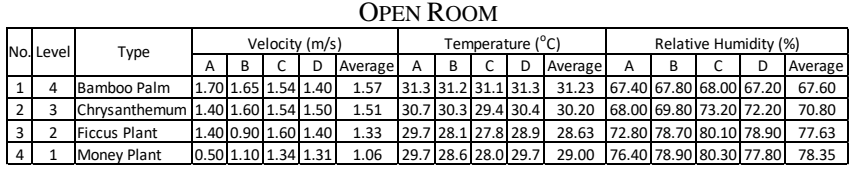

Based on Table VI and Fig. 11, it shows that the highest air velocity is $1.57 \mathrm{~m} / \mathrm{s}$ at level four which is Bamboo Palm while the lowest is $1.06 \mathrm{~m} / \mathrm{s}$, level one Money Plant. Different air velocity recorded on the other two plants which were 1.51 $\mathrm{m} / \mathrm{s}$ for Chrysanthemum and $1.33 \mathrm{~m} / \mathrm{s}$ for Ficcus Plant. The temperature decreased for all plants, the highest temperature was Bamboo Palm which was $31.23{ }^{\circ} \mathrm{C}$ and the lowest was $28.63{ }^{\circ} \mathrm{C}$ demonstrated by Ficcus Plant. It also shows the increased value of $\mathrm{RH}$ for all points taken. The maximum point acquired was $78.35 \%$ on the Money Plant and the minimum point was $67.6 \%$ on the Bamboo Palm. The value of RH gradually increasing from Bamboo Palm, Chrysanthemum, Ficcus Plant, and Money Plant.

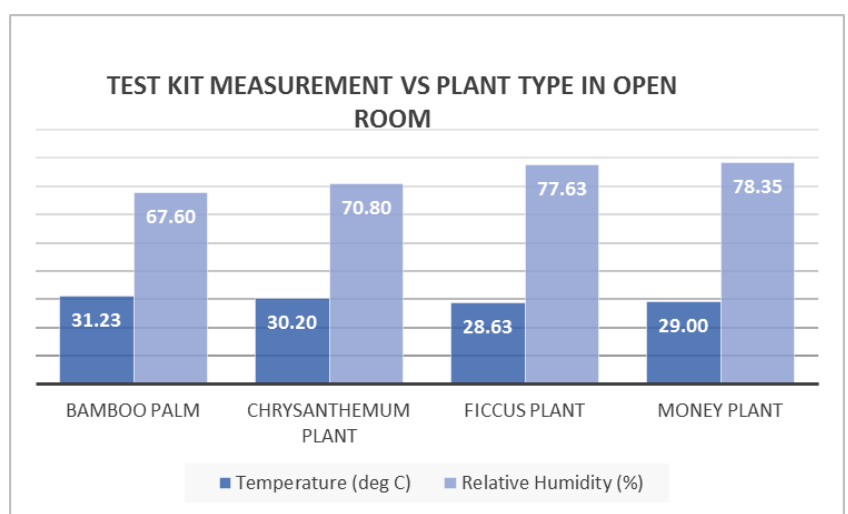

Fig. 11. Test kit measurement in an open room.

\section{F. Total Volatile Organic Compounds (TVOC)}

For the TVOC test, several TVOC products were prepared to produce gasses such as ammonia, formaldehyde, benzene, trichloroethylene, xylene, and toluene. Table VII shows the certain TVOC products and Table VIII shows TVOC readings.

TABLE VII: LIST OF TVOC PRODUCTS

\begin{tabular}{|l|l|}
\hline \multicolumn{1}{|c|}{ TVOC Gas } & \multicolumn{1}{c|}{ Products } \\
\hline Ammonia & Urine (decompose) \\
\hline Formaldehyde & new plywood, foam insulation or combustion of gasoline \\
\hline Benzene & paint, lacquer, varnish, paint remover, industrial solvents, thinner or gasoline \\
\hline Trichloroethylene & refrigerant R134a \\
\hline Xylene & thinner and solvent in paint, pesticide products \\
\hline Toluene & fingernail polish, lacquers, paint, thinner or gasoline \\
\hline
\end{tabular}

TABLE VIII: TVOC READINGS IN A CLOSED ROOM

\begin{tabular}{|c|c|c|c|c|c|c|c|c|c|}
\hline \multirow[b]{2}{*}{ TVOC } & \multirow[b]{2}{*}{$\begin{array}{l}\text { Room } \\
\text { Data }\end{array}$} & \multicolumn{4}{|c|}{ Before Test Kit } & \multicolumn{4}{|c|}{ After Test Kit $(0.15 \mathrm{~m})$} \\
\hline & & $0.25 \mathrm{~m}$ & $0.5 \mathrm{~m}$ & $0.75 \mathrm{~m}$ & $1.0 \mathrm{~m}$ & \begin{tabular}{|c} 
Bamboo \\
palm
\end{tabular} & $\begin{array}{c}\text { Chrysanth } \\
\text { emum }\end{array}$ & Ficcus & $\begin{array}{c}\text { Money } \\
\text { plant }\end{array}$ \\
\hline Formaldeh & 0.004 & 0.0 & 0.0 & 1.99 & 1.5 & 0.006 & 0.011 & 0.006 & 0.004 \\
\hline Bensene $(\mathrm{mg} / \mathrm{m} 3)$ & 0.006 & 0.203 & 0.385 & 9.999 & 9.999 & 0.022 & 0.115 & 0.062 & 0.041 \\
\hline
\end{tabular}

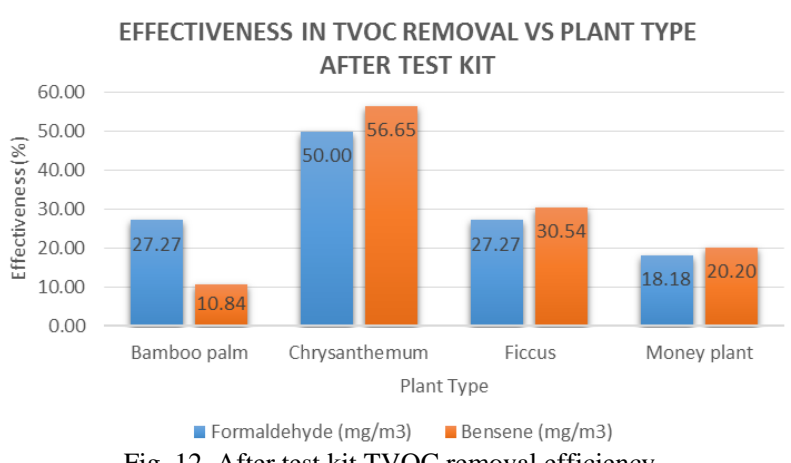

Fig. 12. After test kit TVOC removal efficiency.

As shown in Fig. 12 the highest formaldehyde removal efficiency was $50.0 \%$ by Chrysanthemum and lowest $18.18 \%$ by Money Plant. While for benzene, the highest was $56.65 \%$ also by Chrysanthemum and the lowest was $10.84 \%$ by Bamboo Palm.

As for evaluating affecting factors for different types of air filtration methods such as air velocity, temperature, and relative humidity, it was observed that for air velocity, the structure of plants somehow affects the velocity due to some of the leaves and the main stem blocking the airflow. The temperature profile was separated into two conditions that measure in an open room and another was a closed room. In the closed room, Ficcus Plant recorded the highest temperature drop which was $4.7 \%$ after the evaporative cooling was turned on which increased the humidity in the air 
by $9.1 \%$. Followed closely by Money Plants (Temp $4.2 \%$ \& RH $10.6 \%$ ), Chrysanthemum (Temp $3.2 \%$ \& RH $7.0 \%$ ) and Bamboo Palm (Temp $0.8 \%$ \& RH $3.6 \%$ ). Only small changes recorded if the evaporative cooling was turned off and only allowed the blower fan to run. As in the open room, Ficcus Plant also lead the highest temperature drop which was $9.12 \%$ after the evaporative cooling was turned on which increased the humidity in the air by $16.6 \%$. Followed closely by Money Plants (Temp $7.9 \%$ \& RH $17.6 \%$ ), Chrysanthemum (Temp $4.1 \%$ \& RH $6.3 \%$ ) and Bamboo Palm (Temp $0.9 \%$ \& RH $1.5 \%$ ).

Last but not least, as for the feasibility study of evaporative cooling in Malaysia, this study has found that the potential use of direct evaporative cooling in Malaysia capital is very significant, and can be more than $95 \%$ for the base case if humidity control is not required. For the situation where humidity control may be required, the energy required for dehumidification can be quite significant. It has also been found that the potential use of direct evaporative cooling can be significantly influenced by the characteristic of building and associated cooling system for example design parameters From this experiment, it found that if the test kit power input is much lesser, which is just 196W compared to 1.0HP of air conditioner and portable air purifier out there is about $746 \mathrm{~W}$ and $250 \mathrm{~W}$. As for the evaporation loss and drift loss in the system, it is recorded that water level in test kit aquarium with capacity of 70liters of water reduced $1.5 \mathrm{~cm}$ for every 2 hours.

\section{CONCLUSIONS}

In a conclusion, there are frequent researches conducted on the performance of today's filters in the market and in-room air purifier that is portable, but little studies on the effectiveness of botanical components for air filtration. The highest particulate removal efficiency is $31.58 \%$ for PM5.0 and the lowest is $2.87 \%$ at concentration PM0.5. While for TVOC removal recorded, the highest Formaldehyde removal efficiency is $50.0 \%$ by Chrysanthemum and the lowest, $18.18 \%$ by Money Plant. As for Benzene, the highest removal efficiency is $56.65 \%$ demonstrated by Chrysanthemum, and the lowest is $10.84 \%$ by Bamboo Palm. Based on the particle count and TVOC measurement results, it can be concluded that both types of plants can be implemented into the system as long as the arrangement is correct. Moreover, the selection of certain plants according to the certain application is important. For example, Money Plant and the Bamboo Palm are perfect for smoking areas as they can filter most of TVOC gasses such as formaldehyde, benzene, carbon monoxide and even particulate matter which already been proven based on the data in the chapter before. While Chrysanthemum is perfect in filtering and eliminates toxin ammonia according to NASA Clean Air Study which we failed to acquire the data due to lack of the equipment and funds.

Additionally, the system's ability to remove VOCs and $\mathrm{CO}_{2}$ and modulate temperature and humidity make the device superior to most non-biological systems as general air quality maintenance devices. Nonetheless, further, controlled laboratory experiments are needed to investigate the long term performance of the system, and to better describe the simultaneous removal of PMs, VOCs, and $\mathrm{CO}_{2}$. These experimental research will provide empirical data on which to develop a simulation model that can be used to optimize the system's design, as well as to advance the implementation of the device.

\section{CONFLICT OF INTEREST}

The authors declare no conflict of interest.

\section{AUTHOR CONTRIBUTIONS}

Tan Yong Yih and Zahurin Bin Othman had conducted the research and analysed the data, where Chang Choo Khean rechecked the data analysis and wrote the paper. All authors had approved the final version of the paper.

\section{REFERENCES}

[1] B. F. Yu, Z. B. Hu, M. Liu, H. L. Yang, Q. X. Kong, and Y. H. Liu, "Review of research on air-conditioning systems and indoor air quality control for human health," Int. J. Refrig., vol. 32, 2009, pp. 3-20.

[2] United States Environmental Protection Agency (EPA), Residential Air Cleaners, second ed., A Summary of Available Information, EPA 402-F-09- 002, 2009.

[3] F. R. Torpy, M. Zavattaro, P. J. Irga, and M. D. Burchett, "Assessing the air quality remediation capacity of the JUNGLEFY breathing wall Modular plant wall system," Research Report, School of Life Sciences, Faculty of Science, University of Technology Sydney, 2015.

[4] M. Dela Cruz, R. Müller, B. Svensmark, J. S. Pedersen, and J. H Christensen, "Assessment of volatile organic compound removal by indoor plants - A novel experimental setup," Environmental Science and Pollution Research, vol. 21, no. 13, 2014, pp. 7838-7846.

[5] F. R. Torpy, M. Zavattaro, and P. J. Irga, "Green wall technology for the phytoremediation of indoor air: a system for the reduction of high CO2 concentrations," Air Qual Atmos Health, 2016, pp. 1-11.

[6] Z. Wang and J. S. Zhang, "Characterization and performance evaluation of a full-scale activated carbon-based dynamic botanical air filtration system for improving indoor air quality," Building and Environment, vol. 46, no. 3, 2011, pp. 758-768.

[7] B. Riangvilaikul and S. Kumar, "An experimental study of a novel dew point evaporative cooling system," Energy Build, vol. 42, 2010, pp. 637-644.

[8] S. Jain, "Emulating nature: Evaporative cooling systems," ASHRAE Trans., vol. 114, no. 2, 2008, pp. 421-427.

[9] G. Heidarinejad, M. F. Farahani, and S. Delfani, "Investigation of a hybrid system of nocturnal radiative cooling and direct evaporative cooling," Build. Environ., vol. 45, 2010, pp. 1521-1528.

[10] Jabatan Meteorology Malaysia, 2014.

Copyright (C) 2022 by the authors. This is an open access article distributed under the Creative Commons Attribution License which permits unrestricted use, distribution, and reproduction in any medium, provided the original work is properly cited (CC BY 4.0).

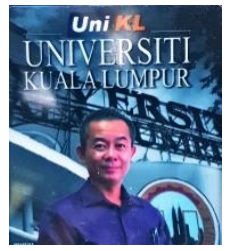

Chang Choo Khean is now pursuing his doctor of philosophy in Mechanical engineering in the University of Putra, Serdang, Malaysia. He has been attached to University of Southampton, United Kingdom for the collaboration research, titled "Climate change implications for buildings and their technical services in tropical and moderate climates", under the sponsorship of British Council, Prime Minister Initiative 2 (PMI2) fund from 2008 until 2010. He has been working in the industry of HVAC for the past twenty four (24) years. He was the service engineer (Head of Department), leading the service team in carrying out the daily job in Topaire Sales \& Services Sdn. Bhd from 1996 until 1997 as his first career. From 1997 until 2001, he was working in Sunline Service Centre Sdn. Bhd as SERVICE ENGINEER, and he was promoted as TECHNICAL MANAGER and appointed as one of the company directors in 2002 until 2008. His area of research is mainly focused on the Climate change, Indoor air quality, Building thermal load, and Energy savings for a building. He has published a few research papers, such as C.K.Chang, Muhammad Amrie B. Tuhaime. Study of wind and solar energy to generate $1 \mathrm{hp}$ air conditioning split unit, Journal of Science and Engineering Technology (jset) (2019); M.M. Syafiq Syazwan, M.Z.M. Yusof, C.K.Chang, M.D. Amir Abdullah. Monitoring of Selected Indoor Air Quality Parameters and Cooling Energy 
Usage in Hotel Restaurant Malaysia, Applied Mechanics and Materials Vol. 564 (2014) pp 250-255; W.T. Chong, S.C. Poh, A. Fazlizan, S.Y. Yip, C.K. Chang, W.P. Hew. Early development of an energy recovery wind turbine generator for exhaust air system, Applied Energy 112(2013) pp. 568-575.

Ts. Chang is currently the senior lecturer in University of Kuala Lumpur Malaysia France Institute, Bandar Baru Bangi, Malaysia. Ts. Chang was the Technical Committee of $20188^{\text {th }}$ International Conference on Environment Science and Engineering (ICESE 2018) at Barcelona, Spain, $9^{\text {th }}$ International Conference on Environment Science and Engineering (ICESE 2019) at Belgium, and the $10^{\text {th }}$ International Conference on Environment Science and Engineering (ICESE 2020) at Vienna. Besides, he was the reviewer for ICESE 2019, $9^{\text {th }}$ International Conference on Environment Science and Engineering and FEBM2020, The Fifth International Conference on Economic and Business Management.

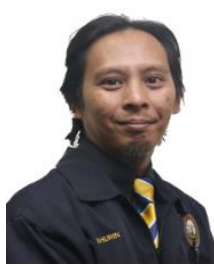

Zahurin Bin Othman was working as a technical supervisor at Jurukon Engineering. Later he joined Isometric Innovations Sdn Bhd in 2000, as technical assistant. After 1 year he was promoted as the BRANCH HEAD for covering the HVAC system at Hospital Kuala Lumpur and Pusat Darah Negara. In 2006 he moved to new company Pro Elite Network Network Sdn Bhd as assistant engineer. His area of research is climate change, Indoor air quality, Building thermal load, Energy savings.

Zahurin is currently the instructor in University of Kuala Lumpur Malaysia France Institute, Bandar Baru Bangi, Malaysia. A part from that he is a member of master trainer for Department of Environmental that involved in phasing out refrigerant project all over Malaysia. He is also involved in giving consultation service to industry in trouble shooting HVAC equipment beside certified all technician that enroll HVACR program. Zahurin is the External Evaluator for Kolej Vokasional Sepang (KV), Technical Support for R290 System, Department of Environment Malaysia, and Technical Trainer for Master Trainer, Department of Environment Malaysia.

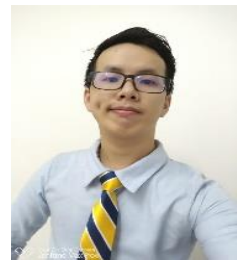

Tan Yong Yih was attached to AET Solutions Sdn. Bhd. in 2018 as technical engineer. He was handling the HVAC systems selection and co-ordinate between Design Department and Project Department for the mobilization of the project. His research area is Climate change, Indoor air quality, Building thermal load, Energy savings.

Currently, Yong Yih is working in Bond M\&E Sdn Bhd. as project engineer and handling the I-Park Hostal Kulai project. Yong Yih is the Certified Graduate Technologist by Malaysia Board of Technologist. 